\title{
"Eu fui, voltei e ninguém viu": um estudo sobre a expectativa de carreira após a repatriação em uma empresa brasileira ${ }^{1}$
}

\author{
"I went, I got back, and nobody saw it": a study on the expected career after repatriation in \\ a Brazilian company
}

\author{
Shalimar Gallon ${ }^{2}$ \\ Angela Beatriz Busato Scheffer ${ }^{3}$ \\ Betina Magalhães Bitencourt ${ }^{4}$
}

\begin{abstract}
Resumo
No mundo corporativo, estudos mostram que os repatriados, ou seja, profissionais expatriados que retornam da sua missão no exterior, tornam-se mais comprometidos com o desenvolvimento de sua carreira após uma experiência internacional. A expatriação agrega conhecimento e experiência profissional, o que pode ser relacionado, pelo repatriado, a uma possível ascensão de carreira ou a um melhor desempenho na organização. Entretanto, quando isso não ocorre, a frustração pode levá-lo a procurar outra empresa que valorize seus conhecimentos, sendo esse um dos grandes desafios empresariais: a retenção dos repatriados. Este estudo tem por propósito analisar a relação percebida entre repatriação e expectativas de carreira profissional por parte dos profissionais que tiveram ou estão tendo uma experiência profissional internacional pela empresa Alpha, organização de grande porte com presença em mais de 100 países e que mantém um processo de expatriação há 12 anos, em 9 países. Assim, foi realizado um estudo de caso com 21 entrevistas, discutidas mediante análise de conteúdo. Como principal achado deste estudo constata-se que os repatriados passam a dar mais valor ao seu desenvolvimento profissional, estabelecendo um maior vínculo consigo mesmos do que com a organização em que trabalham. Como existem falhas por parte da empresa em apresentar um planejamento para aproveitar a experiência desse empregado em posições que demandem mais responsabilidade, alguns entrevistados deixam de pensar em sua carreira dentro da empresa. Desse modo, abrem-se para a busca de outras oportunidades no mercado de trabalho. Por outro lado, os que buscam espaço dentro da organização acabam se percebendo enquanto "um problema" para a empresa.
\end{abstract}

Palavras-chave: Repatriação. Carreira. Expatriação.

Artigo submetido em 29 de novembro de 2012 e aceito para publicação em 06 de março de 2013.

1 Agradecemos à empresa Alpha, que permitiu esta pesquisa colaborando com o fornecimento de dados. À todos os entrevistados, que
se mostraram solícitos no desenvolvimento deste estudo. À CAPES, pelo auxílio financeiro para a condução desta pesquisa.
2 Mestre em administração pela Universidade Federal do Rio Grande do Sul; Doutoranda do Programa de Pós-Graduação em
Administração da Escola de Administração da Universidade Federal do Rio Grande do Sul (UFRGS). Endereço: EA/UFRG - Rua
Washington Luiz, 855, Centro, CEP 90010-460, Porto Alegre - RS, Brasil. E-mail: shalimargallon@hotmail.com
3 Doutora em administração pela Universidade Federal do Rio Grande do Sul; Professora adjunta da Escola de Administração da
Universidade Federal do Rio Grande do Sul. Endereço: EA/UFRGS - Rua Washington Luiz, 855, Centro, CEP 90010-460, Porto Alegre
- RS, Brasil. E-mail: angela.scheffer@ufrgs.br
4 Mestre em administração pela Universidade Federal do Rio Grande do Sul; Doutoranda do Programa de Pós-Graduação em
Administração da Escola de Administração da Universidade Federal do Rio Grande do Sul (UFRGS). Endereço - EA/UFRGS - Rua
Washington Luiz, 855, Centro, CEP 90010-460, Porto Alegre - RS, Brasil. E-mail: betina mb@yahoo.com.br 


\begin{abstract}
In the corporate world, studies show that the repatriates, i.e. expatriated professionals who return from their mission abroad, become more committed to the development of their career after an international experience. Expatriation provides knowledge and professional experience, something which may be related, by the repatriate, to possible career ascension or better performance in the organization. However, when this doesn't occur, frustration can lead him to look for another company which appreciates his knowledge, and this is a major entrepreneurial challenge: the retention of repatriates. This study aims to analyze the perceived relation between repatriation and expectations concerning professional career on the part of professionals who had or have an international professional experience through the Alpha company, a large organization which operates in more than 100 countries and maintains an expatriation process for 12 years, in 9 countries. Thus, a case study was carried out with 21 interviews, discussed through content analysis. As the main finding of this study, one finds out that repatriates start attributing more value to their professional development, establishing a stronger bond with themselves than with the organization where they work. As there're failures on the part of the company to present a planning to take advantage from the experience of this employee in positions which require more responsibility, some respondents stop thinking of their career within the company. Thus, they open themselves to search for other opportunities in the labor market. On the other hand, those who seek space within the organization end up perceiving themselves as "a problem" for the company.
\end{abstract}

Keywords: Repatriation. Career. Expatriation.

\title{
Introdução
}

O processo de expatriação, entendido na sua raiz etimológica latina (expatria, "fora da pátria"), compreende todos os indivíduos que residem temporária ou permanentemente em um país diferente daquele onde nasceram (GONZÁLEZ e OLIVEIRA, 2011). No meio empresarial, a expatriação compreende o processo de um empregado assumir um cargo pela empresa, em país estrangeiro, pelo período de um ou dois anos (DUTRA, 2002; CALIGIURI, 2000). Para fins de conceito da expatriação no mundo corporativo, Dutra (2002) observa que a expatriação é uma prática realizada durante o período de um ano. Caligiuri (2000) ressalta que essa prática deve ser realizada em dois anos, para que seja caracterizada uma expatriação. Nesse estudo, é utilizado o conceito de Caligiuri (2000), por ser convergente com o período de expatriação que a empresa analisada determinou como política desta prática.

Esse processo normalmente ocorre quando as empresas buscam desenvolvimento da liderança dos executivos; expansão de novos mercados; aquisição de conhecimento dos indivíduos; aumento na participação dos mercados de atuação; e/ou transferência de tecnologia (TANURE, EVANS e PUCIK, 2007). O processo de expatriação demanda estruturação por parte da empresa, pois envolve uma série de procedimentos, estratégias e pessoas. Compreende também outros processos, como recrutamento; treinamento; preparação da família; fornecimento dos documentos de todos os envolvidos; acomodação da família e sua adaptação cultural (TANURE, EVANS e PUCIK, 2007).

É importante observar que, na literatura sobre expatriação, não há um consenso sobre as etapas desse processo, tampouco uma subdivisão dos momentos que o compõem. Por isso, muitas vezes, o conceito de expatriado é utilizado para abordar todos os momentos da missão, sendo que o termo repatriado não é muito comum no meio empresarial, embora na literatura esteja mais presente. Nesse estudo, entende-se que a expatriação não constitui apenas o período em que o expatriado vive em outro país, mas que a expatriação está dividida em três etapas: a preparação para a missão; a missão em si; e a volta da missão.

Em relação à última etapa, quando os indivíduos retornam para seu país, os expatriados passam a ser chamados de repatriados. Os repatriados vivenciaram a atuação da empresa em outros países e, assim, passam a fazer parte de uma rede social global que pode dar continuidade às estratégias internacionais. Eles podem ajudar a empresa a estabelecer e expandir os negócios em âmbito internacional, pois possuem conhecimento do contexto cultural e informações específicas sobre o mercado e clientes. Os repatriados têm, 
portanto, um papel importante na organização, uma vez que podem acelerar a transferência de conhecimento das subsidiárias para a matriz e vice-versa. Por essas razões, os repatriados podem representar um importante investimento em capital humano.

Deresky (2004) e Tung (1988) abordam um fator importante na repatriação, que é a adaptação do empregado a seu antigo cotidiano, denominado 'choque cultural reverso'. Este choque faz com que o executivo sinta-se esquecido dentro da organização e, consequentemente, passe a ter dificuldades em sua readaptação na empresa. A readaptação da família também pode ser demorada, pois é possível que seus membros tenham perdido os contatos sociais ou de emprego. Outra dificuldade encontrada na repatriação é a expectativa que os repatriados têm em relação à sua carreira na empresa.

Observa-se que a ascensão na carreira torna-se um dos meios mais expressivos para valorizar o empregado, principalmente quando ele abdica de seu cotidiano para realizar alguma missão por sua empresa, como a expatriação. Lazarova e Caligiuri (2001) destacam que os expatriados, após uma experiência internacional, tornam-se mais comprometidos com o desenvolvimento de sua carreira. Entretanto, Tanure, Evans e Pucik (2007, p. 177) observam que, muitas vezes, isso não ocorre, "pois a expectativa do repatriado de ter um salto na carreira - nutrida desde a discussão sobre a sua expatriação - não corresponde, na maioria das vezes, à visão da empresa". Essa divergência está relacionada a um dos maiores motivos de insucessos da expatriação. Um dos grandes desafios empresariais constitui-se, pois, na retenção dos expatriados (BLACK e GREGERSEN, 1999; STROH, 1995).

A empresa Brookfield Global Relocation Services (2010) realizou uma pesquisa com 120 participantes que representaram as organizações de pequeno, médio e grande porte com escritórios localizados em todo o mundo. Nessa pesquisa foi observado que $38 \%$ dos expatriados deixam a empresa no primeiro ano de repatriação, contra $35 \%$ no relatório de 2009. Ao final do segundo ano de expatriação, esse índice chega a $22 \%$. A alta rotatividade entre os repatriados pode comprometer o recrutamento de futuros expatriados, pois isso mostra aos empregados que as transferências internacionais podem ter um impacto negativo sobre a carreira. Percebe-se, portanto, que o ponto de partida para contornar essa situação é reconhecer e promover os expatriados quando retornam a seu país.

Stahl, Miller e Tung (2002), Suutari (2003), Suutari e Brewster (2003) e Tung (1998) mostram que as pessoas estão cada vez mais direcionadas a ter uma experiência internacional, como forma de melhorar sua carreira em termos de habilidades avançadas e empregabilidade, ao invés de sua carreira dentro da organização atual. Assim, a noção de carreira não precisa, necessariamente, ser analisada sob a perspectiva de carreira organizacional, mas também pode ser observada em nível pessoal construída para agregar competências e habilidades ao indivíduo (STAHL, MILLER e TUNG, 2002).

A experiência que o repatriado obteve assume grande importância, não somente para ele, mas também para a empresa, inclusive financeiramente, pois os gastos demandados com treinamento, preparação e benefícios são altos (BOHLANDER, SNELL e SHERMAN, 2003). Nota-se, portanto, a relevância de estudos sobre a carreira dos repatriados nas empresas, pois um empregado que detém experiência internacional, conhecimento da empresa, do mercado mundial de atuação e tem a prática em cargos gerenciais não deve ser desvalorizado.

Por vezes, as expectativas que surgem em torno de uma expatriação podem ultrapassar a realidade, seja devido à espera de posição e remuneração melhores, como os que foram oferecidos na experiência internacional, seja a expectativa de ter benefícios, autonomia e reconhecimento dos superiores, semelhantes às que obtiveram na missão. Contudo, ao voltar ao país de origem, os repatriados, muitas vezes, passam a receber atividades menos desafiadoras, se comparadas àquelas recebidas no período da expatriação.

Em relação aos desafios das empresas, percebe-se que estão empenhadas em conseguir reter os repatriados e suprir suas expectativas em relação à aplicação do conhecimento adquirido no exterior. Considera-se que há importante aprendizado para os trabalhadores neste processo e que isto representa grande diferencial 
competitivo no mercado de trabalho para as empresas, entretanto, ainda pouco valorizado. Assim, torna-se fundamental pensar em estratégias ou práticas e políticas de expatriação que contemplem a etapa da repatriação.

Neste estudo, buscou-se analisar quais as expectativas geradas pela repatriação na vida dos profissionais no meio empresarial, que estão tendo ou tiveram uma experiência internacional, e sua relação com a carreira. Nas próximas seções são elucidadas as possibilidades e a expectativa de carreira dos profissionais repatriados, bem como os procedimentos metodológicos que conduziram este estudo. Por fim, apresenta-se a análise dos resultados e as considerações finais do estudo.

\section{Ampliando e Compreendendo as possibilidades de Carreira}

O tema carreira é amplo por apresentar diversas abordagens. Impulsionado pelas mudanças sociais, econômicas, políticas e culturais, o conceito de carreira tem passado por alterações, ao longo dos anos. De modo mais tradicional, para Dutra (2007), a carreira está relacionada à mobilidade ou à estabilidade ocupacional a ser seguida por uma pessoa, ou seja, é o caminho estruturado e organizado, no tempo e espaço, que pode ser delineado por um indivíduo. Blau (2001) analisa a carreira como a representação do padrão de experiências associadas ao trabalho de uma pessoa por toda a sua vida.

Embora normalmente a carreira esteja ligada às ocupações do trabalho que envolvem posições de remuneração, tais como responsabilidades, status, prestígio e poder, ela também pode ser analisada sob a perspectiva das donas de casa, dos pais e dos trabalhadores voluntários que querem aumentar seus conhecimentos e responsabilidades, através de suas experiências (IVANCEVICH, 2008). Inkson (2007) observa que esse tipo de atividade ou até mesmo um hobby envolvem experiências que são relevantes para a carreira, bem como para o desenvolvimento de competências individuais. A carreira não precisa, portanto, estar necessariamente vinculada a uma atividade remunerada nem a uma organização.

Dentre as abordagens em administração, Bendassolli (2009) mostra que, comumente, os estudos sobre carreira são conduzidos em dupla perspectiva: a do indivíduo (carreira subjetiva e estratégias de carreira) e a da organização (carreira como estruturas e rotinas). Na perspectiva da organização, Dutra (2007) aborda três tipos de carreira (estruturas em linha, estruturas em rede, estruturas paralelas), as quais se referem à estruturação das possibilidades de crescimento dentro da organização. Nesse sentido, a carreira está envolvendo uma série de estágios, sendo que a ocorrência de transições reflete as necessidades, os motivos e as aspirações individuais, além das expectativas e imposições da organização. Na condução dessas transições, maiores responsabilidades têm sido delegadas às pessoas, na expectativa de que o planejamento de carreira seja uma forma de elas se tornarem empreendedoras de si mesmas. Fala-se em uma gestão compartilhada de carreira entre a empresa e a pessoa (DUTRA, 2007).

Chanlat (1995) descreve quatro tipos de carreira: burocrática, profissional, empreendedora e sociopolítica. A carreira burocrática refere-se às estruturas burocráticas da empresa, na qual o profissional busca a ascensão na hierarquia organizacional, estando cada nível alcançado relacionado com responsabilidades, salário e vantagens do cargo. A carreira profissional refere-se ao conhecimento e às experiências acumuladas com o cargo, desenvolvendo, assim, maior comprometimento com a profissão do que com a organização. A carreira empreendedora está relacionada com as atividades de uma organização independente, delineadas por uma pessoa. Esse tipo de carreira pode ser observado principalmente em artistas, comerciantes e empresários de pequenas e médias empresas. A carreira sociopolítica refere-se às habilidades sociais e ao poder de relações que uma pessoa possui.

Nos últimos tempos, a concepção de carreira voltada para uma empresa vem se transformando em uma concepção mais individualizada, pela qual as pessoas são impulsionadas a tomarem decisões sobre o próprio destino, dentro da noção de empregabilidade. Tal como referido por Bendassoli (2009), carreira, em uma 
visão mais contemporânea, passou a englobar um projeto de vida. Tal mudança reflete as profundas transformações do trabalho nas últimas décadas, com destaque para a nova relação sujeito-trabalho, marcada por maior vínculo do indivíduo consigo mesmo do que com a organização em que trabalha.

Nesse contexto, demanda-se do próprio indivíduo a responsabilidade pelo planejamento e pela administração da própria carreira. Observando outros tipos de carreira, os estudos de Hall (1996) revelam que a carreira do século XXI é proteana, conduzida pela própria pessoa e não mais pela organização. O contrato de carreira não é um pacto com a empresa, mas um acordo entre o indivíduo e seu próprio trabalho. Essa carreira deve ser reinventada pelo indivíduo, tanto como pessoa, como na mudança de ambiente, com base no crescimento de um processo de aprendizagem contínua. Dentro dessa carreira, a maior parte do aprendizado vem de atribuições de trabalho, que se estendem por novos caminhos, e das conexões com outras pessoas no ambiente de trabalho, sejam elas colegas de trabalho, subordinados, clientes, superiores ou membros de redes formais e informais (HALL, 1996).

Fontenelle (2005) diz que a carreira proteana pode ser entendida como uma metáfora da carreira de autogestão. A carreira proteana tem a concepção de um indivíduo flexível, capaz de gerenciar o presente e o futuro de seu trabalho, assumindo o sucesso e o fracasso. Administrar a carreira direciona para o desenvolvimento da capacidade de responder, por si mesmo, às demandas da realidade, assumindo diferentes formas ou papéis, continuamente pressionado pela necessidade de capacitação para obter vantagem em um ambiente de constantes mudanças (FONTENELLE, 2005).

As mudanças no contexto e, consequentemente, no ambiente organizacional, têm sido geradoras de transformações nas práticas administrativas, o mesmo ocorrendo com a noção de carreira. Em um contexto de internacionalização, torna-se relevante investigar de que modo a carreira e a repatriação estão relacionadas devido à representatividade que a experiência tem na carreira profissional do executivo.

\section{Expectativa de Carreira Após a Repatriação}

Existem estudos internacionais que observaram os impactos da expatriação sobre a carreira do indivíduo, seja relacionando-a como um aspecto positivo ou negativo na carreira dos gestores (TUNG, 1998). Esse impacto está articulado diretamente ao suporte, às práticas e às políticas que a empresa tem em relação aos expatriados, quando eles retornam da missão.

Quando os repatriados "globalizados" voltam para casa, eles são esperados para compartilhar seus conhecimentos, habilidades e redes de estratégia internacionais com os colegas (HERMAN e TETRICK, 2009). No entanto, no momento em que o repatriado volta para a sua empresa e percebe que as habilidades, as competências e a experiência adquiridas no estrangeiro não estão sendo utilizadas, pode se sentir frustrado e até pedir demissão (STROH, GREGERSEN e BLACK, 1998; SUUTARI e BREWSTER, 2003; TUNG, 1988). Consequentemente, ele pode reagir mudando para outra empresa que valorize sua experiência internacional e as competências adquiridas (KOHONEN, 2008).

Esse confronto de objetivos e a não valorização das novas habilidades dos expatriados pode acarretar índices indesejáveis de demissões na organização. Altos índices de turnover comprometem a capacidade da empresa de recrutamento de futuros expatriados, sinalizando, implicitamente, para os outros empregados que as transferências internacionais podem ter impacto negativo sobre a carreira (LAZAROVA e CALIGIURI, 2001).

Considera-se, ainda, que os executivos que desejam seguir uma carreira internacional devem gerir suas próprias experiências, para se tornarem competitivos e assim permanecerem no âmbito dos negócios. Contudo, eles não podem confiar inteiramente nas organizações para facilitar o desenvolvimento pessoal, 
pois, às vezes, os objetivos de cada parte são incompatíveis (LAZAROVA e CERDIN, 2007; HERMAN e TETRICK, 2009).

Nesse contexto, a organização tem que traçar estratégias para conseguir reabsorver o indivíduo (TUNG, 1988), pois os custos com as falhas nas operações internacionais podem ser altos, principalmente quando esses estão relacionados à empresa tanto em termos financeiros, quanto na perspectiva individual da carreira do colaborador. Em relação à repatriação, essa pode ser prejudicada quando as expectativas de progressão na carreira não são realizadas. As falhas também podem ser arrasadoras para a autoestima do expatriado, se a missão estiver associada a uma missão malsucedida (WEBB e WRIGHT, 1996; TUNG, 1981; MENDENHALL e ODDOU, 1985; BLACK e GREGERSEN, 1999).

Outros estudos mostram que, apesar de os expatriados acreditarem que a missão internacional vem acompanhada de um avanço na carreira profissional, $60 \%$ dos expatriados não têm uma chance garantida de ascensão na carreira, quando retornam para a sede da organização. $O$ índice dos expatriados que viajam com a promessa de ter um cargo do mesmo nível daquele assumido internacionalmente chega a 33\%, no entanto apenas 7\% têm oportunidade de obter uma promoção (TUNG, 1998).

Tung (1988), em um estudo com empresas europeias, japonesas e australianas para observar como era percebida a repatriação sob a perspectiva da carreira, constatou que grande parte destas empresas observava a expatriação como uma forte sinalização para uma subsequente promoção. $O$ autor acrescenta que essa pesquisa vai de encontro à outra, realizada na época com empresas multinacionais nos Estados Unidos. Essa pesquisa mostra que apenas $4 \%$ das organizações em análise, que tinham missões no exterior, consideravam que a expatriação estava sendo vinculada a um aspecto positivo na carreira do indivíduo.

Essa diferença de perspectiva pode ser relacionada a três razões. A primeira situa-se em relação às mudanças organizacionais, realizadas durante o tempo em que o indivíduo esteve no exterior, as quais podem tornar sua posição na organização sede como redundante ou periférica. A segunda razão relaciona-se aos avanços tecnológicos na sede, que também podem tornar obsoletos as competências e o conhecimento do indivíduo. A última razão dessa diferença é a predominância de uma síndrome comum em empresas americanas: "o que os olhos não veem, o coração não sente", ou seja, devido à ênfase na atividade doméstica, muitas pessoas temem que, se forem removidas da sede da empresa por um longo período de tempo, elas estarão fora do fluxo principal da empresa e, portanto, ignoradas para futuras promoções (TUNG, 1988).

As pesquisas de Tung (1998) mostram que grande parte dos expatriados percebe a experiência internacional como impacto positivo em sua carreira. Essa percepção pode estar relacionada à carreira interna do expatriado, a qual está associada à aquisição de habilidades, desenvolvimento pessoal e reforço da carreira profissional, mesmo que a carreira não seja desenvolvida dentro da organização em que ele se encontra no momento (STAHL, MILLER e TUNG, 2002; TUNG, 1998). A carreira interna envolve, portanto, um senso subjetivo que se refere ao lugar ao qual a pessoa deseja chegar com seu trabalho, enquanto a carreira externa aborda o avanço do colaborador dentro da hierarquia da empresa (SCHEIN, 1996).

Os estudos de Stahl, Miller e Tung (2002) mostram que 89\% dos repatriados acreditam que a experiência internacional tem impacto positivo em sua carreira, mesmo que não melhore sua posição dentro da organização. Isso mostra que os expatriados, quando aceitam a missão internacional, já estão pensando em sua carreira interna, analisando as habilidades que a missão vai agregar a eles e não à organização.

Tung (1998) também aborda que a carreira interna está direcionada à carreira 'sem fronteiras' e a organizações 'sem fronteiras', na quais os indivíduos podem gerir suas carreiras. Este contexto 'sem fronteiras' é um cenário provável em que as atividades de investimento na carreira, através do apoio de práticas da organização, podem incentivar a retenção, após o repatriamento. Isso não implica, porém, necessariamente, uma influência positiva na lealdade do colaborador, em longo prazo (LAZAROVA e CALIGIURI, 2001). 
Observa-se que as expectativas criadas pelos expatriados são muitas, apesar de eles saberem em que condições irão e em quais voltarão, em função do contrato assinado com ambas as organizações (matriz e subsidiária). Com isso, ressalta-se a perspectiva de carreira interna e externa (STAHL, MILLER e TUNG, 2002; TUNG, 1998), o que permite enxergar que a expatriação acaba por agregar mais à carreira interna do que à externa, podendo ser um fator responsável pelos índices de demissão de repatriados.

Percebe-se, pois, a necessidade de conciliar as expectativas de crescimento do repatriado com os objetivos da empresa. Embora não haja espaço para todos os empregados ocuparem cargos gerenciais, é importante que a empresa encontre uma forma de valorizar o repatriado; afinal, ele deu importante contribuição para o desenvolvimento da organização e se desenvolveu juntamente a ela. Cabe à empresa, portanto, encontrar a melhor forma de continuar essa parceria.

\section{Procedimentos Metodológicos}

A presente pesquisa consiste em um Estudo de Caso que, de acordo com a concepção de Yin (2005, p. 28), “faz-se uma questão do tipo 'como' ou 'por que' sobre um conjunto contemporâneo de acontecimentos sobre o qual o pesquisador tem pouco ou nenhum controle". O estudo de caso é vantajoso quando o pesquisador deseja "compreender os processos e interações sociais que se desenvolvem nas organizações, situando-os no contexto histórico - atual e/ou passado - no qual estão imersos" (GODOI e MATTOS, 2006, p. 127). Também é considerada uma pesquisa qualitativa, que, de acordo com Demo (2000, p. 152), tem o intuito de analisar "o lado subjetivo dos fenômenos, buscando depoimentos que se transformam em dados relevantes".

O estudo foi realizado na empresa Alpha (nome fictício dado para a organização em estudo, a fim de preservar sua identificação) do setor metalúrgico no Rio Grande do Sul. Esta empresa possui 22 mil empregados, distribuídos em nove países além do Brasil (África do Sul, Argentina, Austrália, China, Colômbia, Egito, Índia, México e Rússia). Com isso, a empresa demanda que seus empregados assumam cargos de gerência nas diversas partes do mundo em que ela tem sede. O programa de expatriação iniciou-se há 12 anos e, atualmente, conta com cerca de 90 expatriados que foram convidados a assumirem os desafios de uma carreira internacional.

A empresa tem presença em mais de 100 países dos cinco continentes. Sua estrutura possibilitou que ela obtivesse $8 \%$ do mercado global, o que equivale a 16 mil unidades vendidas, em 2008. Em 2012, foi totalizada a produção de 350 mil unidades. Em relação ao mercado brasileiro, a empresa Alpha é líder em seu segmento e se posiciona entre as maiores fabricantes do mundo. Devido a sua representatividade no mercado, a sua internacionalização e à busca por novas ferramentas para aperfeiçoar a prática de expatriação, esta empresa foi escolhida para a realização desse estudo.

A coleta de dados foi realizada por meio de entrevistas, baseadas em roteiro de perguntas semiestruturado, construído com foco nos objetivos do estudo e alicerçada na literatura consultada. O roteiro passou por um teste-piloto com três pessoas: um repatriado sem vínculo com a empresa e dois expatriados da organização. A escolha pela realização de entrevistas como técnica de coleta se justifica em função de permitir maior profundidade na investigação.

Além dos responsáveis pela expatriação na área de $\mathrm{RH}$, foram definidos 4 grupos de entrevistados, conforme elucida o Quadro 1: (i) Grupo 1: empregados que estão em expatriação por menos de 8 meses; (ii) Grupo 2: empregados que estão em expatriação por mais de 9 meses; (iii) Grupo 3: repatriados; e (iv) Grupo 4: empregados que foram expatriados pela empresa, retornaram para suas atividades normais no Brasil, mas hoje não trabalham mais para a empresa. Vale ressaltar que a empresa possui como política que o contrato dos expatriados deve ser pelo período de um ano, podendo ser renovado por mais um ano; portanto, o empregado que fica um ano fora da empresa é considerado um 
expatriado, sendo esse considerado o recorte da pesquisa para a determinação de quem seria um expatriado.

\section{Quadro 1}

Grupos de Entrevistados

\begin{tabular}{|l|l|c|}
\hline \multicolumn{1}{|c|}{ Grupo } & \multicolumn{1}{c|}{ Situação } & Participantes \\
\hline Grupo 1 & Estão no início da expatriação & 4 \\
\hline Grupo 2 & Estão maior tempo em expatriação & 4 \\
\hline Grupo 3 & Repatriados & 7 \\
\hline Grupo 4 & Repatriados desligados da empresa & 4 \\
\hline Área de Recursos Humanos & Representantes da área de expatriação & 2 \\
\hline
\end{tabular}

Fonte: Elaboração das autoras (2012)

No total, foram entrevistadas 21 pessoas: 2 responsáveis pela área de expatriação, quatro expatriados do Grupo 1, quatro expatriados do Grupo 2, sete repatriados do Grupo 3 e quatro ex-empregados repatriados do Grupo 4. O Quadro 2 mostra o perfil dos expatriados entrevistados a fim de mostrar as características comuns entre eles.

\section{Quadro 2}

\section{Resumo do Perfil dos Entrevistados}

\begin{tabular}{|c|c|}
\hline Categorias & Características \\
\hline $\begin{array}{l}\text { 1. Perfil dos Expatriados } \\
\text { entrevistados }\end{array}$ & $\begin{array}{l}\text { - Escolaridade superior (18 entrevistados); } \\
\text { - Faixa etária elevada (média de idade: } 41 \text { anos); } \\
\text { - Tempo de casa elevado (13 anos); } \\
\text { - Sexo masculino (19 expatriados); } \\
\text { - Possuem experiência internacional anterior (12 entrevistados) }\end{array}$ \\
\hline 2. Família & - Não é levado em consideração \\
\hline 3. Países de Expatriação & - Índia é o país que mais demanda expatriado \\
\hline 4. Tempo do Contrato & - Em média, a expatriação tem duração de 2 anos \\
\hline 5. Cargo & $\begin{array}{l}\text { - A maioria retorna para um cargo similar ao que tinha antes da } \\
\text { expatriação }\end{array}$ \\
\hline 6. Total de Entrevistados & $\begin{array}{l}\text { - } 19 \text { expatriados; } \\
\text { - } 2 \text { pessoas responsáveis pela área de expatriação }\end{array}$ \\
\hline
\end{tabular}

Fonte: Elaboração das autoras (2012) 
Em relação aos cargos assumidos na expatriação, oito assumiram a função de gerente; três, de coordenador; dois, de supervisor; três, de diretor; um, de Chief Executive Officer (CEO); um, de auxiliar; um, de assistente. Todas as posições envolviam maiores responsabilidades em relação ao cargo anterior.

Em relação ao cargo da volta, dois expatriados assumiram o cargo de diretor; dois, de gerente; dois, de coordenador; dois, de supervisor; dois, de analista; um, de instrutor e um, de comprador. Assim, ao comparar o cargo que o empregado teve na expatriação com o que possui atualmente, cinco expatriados mantiveram o mesmo cargo, e sete tiveram um cargo inferior. Em relação ao cargo com o qual o expatriado voltou, comparado com o cargo que ele tinha antes da expatriação, três pessoas subiram de cargo; oito se mantiveram no mesmo cargo; uma teve um cargo inferior ao anterior à expatriação. Em relação a oito expatriados, não há como fazer essa comparação, pois ainda não voltaram da missão. No momento da entrevista, apenas um já sabia qual seria seu futuro cargo, pois faltavam cinco meses para ele retornar ao Brasil.

Considerando esta última questão envolvendo o cargo, ressaltam-se dois fatores. O primeiro em relação aos cargos da ida e da volta: apesar de a nomenclatura do cargo não mudar, há possibilidade de maiores responsabilidades atreladas àquele cargo, o que atribui mais importância à função exercida (crescimento horizontal). O segundo fator relaciona-se ao cargo assumido na expatriação, que, apesar da nomenclatura, na expatriação, pode ter as responsabilidades e o campo de ação ampliados, pois a estrutura da empresa demanda que o empregado seja mais dinâmico e tenha visão global da empresa, o que ele possivelmente não teria, caso tivesse esse mesmo cargo aqui no Brasil, em função das competências que lhe são requeridas.

Quanto aos entrevistados, salienta-se que não houve distinção de sexo, escolaridade, faixa etária, renda, cargo, nem país para o qual foram enviados. Se houvesse dependência de cargo, sexo, idade ou escolaridade dos indivíduos na organização, não haveria participantes suficientes para preencher os quatro grupos de pesquisa.

As entrevistas, na primeira fase, foram realizadas com duas pessoas responsáveis pela expatriação na empresa, buscando-se identificar as práticas e as políticas de carreira e expatriação da mesma. Quanto aos expatriados/ repatriados, as entrevistas foram realizadas em duas unidades da empresa no Estado do Rio Grande do Sul. Optou-se por essas unidades devido à proximidade, o que facilitou o contato com a empresa e com os participantes, tendo sido possível, assim, realizar as entrevistas nos momentos mais apropriados tanto para a organização quanto para os entrevistados.

$\mathrm{Na}$ primeira visita à empresa, foi decidido, em conjunto com o RH, o nome das pessoas a serem entrevistadas, de acordo com os pré-requisitos da pesquisa (tempo de expatriação). Foi decidido que os responsáveis pelo RH marcariam o contato com as pessoas selecionadas, para mostrar que a empresa apoiava a pesquisa e também por serem pessoas de cargos mais importantes, requerendo uma intermediação para que fosse possível agendar um horário. $\mathrm{O}$ RH tinha acesso a informações sobre as viagens dos expatriados que estavam fora do Brasil, o que possibilitou que 4 entrevistados dos grupos 1 e 2 fossem entrevistados pessoalmente. As entrevistas foram realizadas em uma sala particular, na qual não havia movimentação de outras pessoas. Em dois casos, foi necessário deslocamento até o setor de trabalho, em função do tempo escasso dos entrevistados, mas a entrevista também decorreu em uma sala separada. As entrevistas do Grupo 4, em função de a empresa não divulgar os nomes de ex-empregados, foi feito o contato com um entrevistado que participou do pré-teste, mas que, três meses depois de participar da entrevista, deixou a organização. Além de este participante ter sido entrevistado novamente, ele indicou os outros três entrevistados do mesmo grupo.

Quanto aos expatriados que estavam fora do país, as entrevistas foram realizadas via internet, com ferramentas de conversação, como MSN e Skype. Além de permitirem interação entre o entrevistador e o entrevistado, elas possibilitam também o contato visual, assim não se perdendo a característica da entrevista de deixar perceber as expressões dos entrevistados ao falarem sobre as expectativas, desafios e dificuldades enfrentadas. Além 
disso, essas ferramentas são familiares aos entrevistados, por ser seu principal meio de comunicação com o Brasil.

Para a análise de dados coletados nas entrevistas, foi utilizada a técnica de análise de conteúdo, que tem o intuito de descobrir e ir além da transparência dos dados (BARDIN, 2004). Em um primeiro momento, realizou-se a transcrição das entrevistas e, diante das entrevistas digitadas, foi realizada uma leitura flutuante, a fim de estruturar as categorias. Dessa maneira, foi realizado um recorte dos parágrafos em comum e esses foram organizados dentro de três macrocategorias previamente definidas: expatriação, repatriação e carreira. A partir dessa estruturação, realizou-se uma leitura mais aprofundada, que buscou observar dados aparentemente escondidos, para melhor sistematizar as categorias. A partir disso, surgiram 12 categorias de análise englobadas nas macrocategorias da seguinte maneira: (a) expatriação: (i) preparação para expatriar e o papel do RH; (ii) Família: participação no processo; (iii) Trabalho e desempenho: perfil para expatriar; (iv) Adaptação e o impacto do grupo; e (v) Significado da expatriação; (b) repatriação: (vi) Adaptação do repatriado e o papel do RH; (vii) Recolocação do expatriado; e (viii) Significado da repatriação; e (c) carreira: (ix) Percepção sobre carreira; (x) Planejamento da carreira; (xi) Expectativa de carreira; e (xii) Relevância da expatriação na carreira. O Quadro 3 mostra as 12 categorias de análises em suas respectivas macrocategorias.

Quadro 3

Sistematização das Categorias de Análise

\begin{tabular}{|c|c|}
\hline Macrocategorias & Categorias de análise \\
\hline \multirow{5}{*}{ Expatriação } & Preparação para expatriar e o papel do RH \\
\hline & Família: participação no processo \\
\hline & $\begin{array}{c}\text { Trabalho e desempenho: em jogo o perfil para } \\
\text { expatriar }\end{array}$ \\
\hline & Formas encontradas de viver na expatriação \\
\hline & Significado da expatriação \\
\hline \multirow{3}{*}{ Repatriação } & Adaptação do repatriado e o papel do RH \\
\hline & Recolocação do expatriado \\
\hline & Significado da repatriação \\
\hline \multirow{4}{*}{ Carreira } & Percepção sobre carreira \\
\hline & Planejamento da carreira \\
\hline & Expectativa de carreira \\
\hline & Relevância da expatriação na carreira \\
\hline
\end{tabular}

Fonte: Elaboração das autoras (2012) 
Após as categorias finais de análise, foi realizada a interpretação dos dados bem como a relação com a literatura utilizada neste trabalho. São exploradas neste artigo somente duas categorias de análise em virtude de ser um recorte dos resultados de uma dissertação de mestrado.

\section{Expectativa de Carreira dos Repatriados}

A expectativa de carreira dos repatriados é aqui discutida com base em duas macro-categorias: repatriação e carreira, mais especificamente nas categorias recolocação e significado da repatriação (referentes à repatriação) e expectativa de carreira e relevância da expatriação na carreira (referente à carreira), o que será agora discutido.

Antes, cabe destacar que nas entrevistas com a área de RH, foi identificado como o principal objetivo da expatriação a necessidade de levar conhecimento para as empresas subsidiárias e de ter pessoas de confiança para o gerenciamento das unidades. Apesar de a empresa possuir uma estrutura global, elevada capacidade de produção, liderança em seu segmento de mercado e reconhecimento no mercado internacional, possui características de uma gestão familiar. Por isso, as práticas de RH ainda se encontram em fase de aprimoramento, devido à reduzida estrutura que a área ocupa na empresa.

\section{A Repatriação dos executivos}

A análise dos resultados em relação à repatriação visou mostrar os principais fatores referidos pelos entrevistados sobre o retorno ao Brasil, durante (expectativas no caso dos que estão ainda em expatriação) e após a experiência internacional (repatriados). No primeiro momento, abordam-se as expectativas de retorno e de crescimento dentro da organização. Posteriormente, são relacionadas as questões do aprendizado obtido, do desempenho do trabalho realizado no exterior e seu impacto no retorno do entrevistado ao país de origem. Por fim, apresenta-se a etapa da recolocação e como esta foi conduzida.

De acordo com os entrevistados, no início da experiência de expatriação, os empregados não têm muita preocupação com sua volta e deixam para pensar nisso quando o contrato estiver terminando. Alguns entrevistados do Grupo 1 (que estão no início da expatriação) questionam-se sobre seu futuro, pois não há um posicionamento formal da empresa matriz sobre a recolocação. Isso mostra que o expatriado vai para a missão sem ter discutido perspectivas de carreira e possibilidades de progressão. Os participantes relatam que seria importante haver, junto com a empresa, um planejamento da volta dos repatriados, o qual permitisse que eles ocupassem um cargo em que pudessem utilizar o aprendizado decorrente da expatriação. Esse aproveitamento seria útil para os empregados, que se sentiriam mais valorizados, e a empresa estaria melhor aproveitando o retorno do seu investimento.

É que isso aí acaba indo contra o planejamento que a gente tem de carreira. Tu imaginas que eu ficaria sentado em uma cadeira por um ano dentro da empresa, esperando sair a oportunidade dentro da minha área, dentro daquilo que eu sei fazer? (...) Eu não poderia voltar para o Brasil se a empresa não planejar o retorno agora para uma posição que seja hierarquicamente semelhante do que eu tenho aqui, eu não vou voltar, porque os dois passos que eu dei para frente, eu estaria dando três para trás (ENTREVISTADO E GRUPO 2).

Independente do grupo em que se encontram, os entrevistados apresentam expectativas semelhantes quanto à recolocação: assumir um cargo no qual possam desenvolver o que aprenderam. 
Além de se valorizarem mais, pelo conhecimento aprendido, e de perceberem novas oportunidades, eles entendem que a experiência traz consigo importante função estratégica, com conhecimentos novos que deveriam ser utilizados pela empresa. De acordo com os estudos de Herman e Tetrick (2009), na volta dos repatriados, espera-se que eles compartilhem seus conhecimentos adquiridos. Por vezes, entretanto, eles percebem que esta experiência não está sendo devidamente valorizada e acabam optando por deixar a empresa, conforme abordado por Stroh, Gregersen e Black (1998), Suutari e Brewster (2003) e Tung (1988).

Neste caso estudado, observa-se que não há preocupação por parte da empresa, para que seja utilizado o aprendizado da expatriação, embora, em alguns casos, esse aproveitamento aconteça. Por exemplo, o Entrevistado M, que está sendo repatriado em uma posição estratégica da empresa, compreende a falha existente, mas quer aproveitar melhor o conhecimento dos expatriados para amenizar esse problema.

Fiquei, porque era uma função que, em três horas do dia, fazia tudo que tinha que fazer, não exigia nada lá. Então, me senti de férias, seis meses de férias e por mais uma vez eu cheguei para o meu chefe e disse: "vocês tão perdendo dinheiro esse mês, eu não paguei meu salário, eu não gosto disso". Ele me olhou e disse: "calma, tenha paciência, uma hora vai aparecer alguma coisa". É uma coisa que me incomodou bastante (ENTREVISTADO N GRUPO 3).

Olha, o meu processo de repatriação foi assim: quando eu voltei de Portugal, saí de uma área de compras e voltei para uma área de pós-vendas. Uma coisa nada a ver com a outra, mas para mim serviu a experiência, não tenho nada a reclamar. Mas, de novo, eu passei um ano fora, desenvolvendo habilidades em uma área e voltei para outra área nada a ver com essa (ENTREVISTADO T - GRUPO 4).

O desempenho do empregado durante a expatriação pode impactar sua recolocação na volta. Independente do grupo analisado, o feedback recebido dos superiores na missão, sinalizando que o trabalho realizado atingiu os objetivos da empresa, forças e fraquezas desenvolvidas etc., foram destacadas como fundamentais, embora nem sempre tenham ocorrido. Além disso, alguns depoimentos mostram que, por vezes, o RH não tem conhecimento do desempenho do empregado, pois a informação não lhe é repassada.

Então, tem pessoas que a gente até acaba identificando aqui, o cara vem para cá e se destaca como supervisor, uma pessoa que conhece tecnicamente e que passa a orientar pessoas, que passa a administrar pessoas [...] E quando volta para o Brasil, se a pessoa que estava aqui e viu isso, não encaminhar para ao RH, ela não vai conseguir fazer isso, pode acabar frustrando o profissional (ENTREVISTADO B - GRUPO 1).

Apesar de a falha dos supervisores das filiais em não repassarem as informações sobre o desempenho dos expatriados, a área de Recursos Humanos não poderia se eximir dessa responsabilidade. O RH deve ter controle sobre o desempenho dessas pessoas para que possa recompensá-las, ou não, pelo trabalho realizado, impactando sobre a retenção desses profissionais.

É ressaltado que o cargo não é o mais importante, mas as atividades e as responsabilidades a serem desenvolvidas na empresa, pois os repatriados não querem ficar "jogados em um canto até que seja arrumado algo para fazer" (Entrevistado P - Grupo 3). Até mesmo aqueles que voltaram como gerentes demonstraram insatisfação com seu cargo, pois não recebem desafios e também por terem visto "que lá fora as coisas acontecem, e aqui não" (Entrevistado L - Grupo 3), referindo-se à forma "engessada" que a empresa apresenta.

Lá fora você vira montador, você é controle de qualidade, você é dono da empresa. A gente faz de tudo um pouco, a dinâmica é diferente de trabalho (ENTREVISTADO J - GRUPO $3)$.

São 61anos arraigado e essa empresa chegou aonde chegou não foi de graça, foi trabalhando, mas isso é um sentimento que não é só eu, expatriado, que tenho, são muitos expatriados que têm um sentimento de rejeição de comprometimento. Eu trabalhava bem lá 
fora, agora por que na minha casa [empresa matriz] eu trabalho menos, no sentido de dar resultado? Porque não te deixam. Porque tu te deparas com os de cima e para os lados: "Ah não! Aqui é meu, aqui tu não podes entrar. Não pode sair do quadrado e isso é frustrante" (ENTREVISTADO L - GRUPO 3).

Um dos diretores da empresa, quando questionado sobre a recolocação dos repatriados, observou que isso acontece naturalmente, e que o retorno do desempenho realizado viria com o tempo, citando como exemplo o entrevistado L, que foi bem recolocado. Entretanto, este observou que "hoje, mais do que antes [penso em sair da empresa]" (ENTREVISTADO L - GRUPO 3).

Outro entrevistado observa ainda as divergências entre o ponto de vista do empregado e o da empresa, pois, quando ele foi repatriado, foi colocado em outra área, o que, para a empresa, representava crescimento para o empregado. Entretanto, na visão deste, tal mudança a nada se agregou, em função da atividade bem mais complexa que ele realizara durante a experiência internacional. Isso é observado por Dutra (2007), quando ressalta a importância de a empresa conseguir conciliar suas expectativas com as do empregado.

Em relação à experiência do Entrevistado J, sua primeira expatriação foi para o México, porém, quando voltou, sentiu-se muito desmotivado por razões semelhantes às de outros repatriados. Ele viu, então, a oportunidade de ir para a Índia como forma de achar novo desafio dentro da empresa. No retorno da segunda expatriação, ele estava novamente insatisfeito, pensando que sua repatriação seria igual à primeira. No entanto, a empresa conseguiu realocá-lo em uma área em que se sentiu à vontade e desafiado, e hoje consegue ver um futuro dentro da organização. É interessante observar, neste caso, que, quando questionado sobre o fato de querer sair da empresa, no retorno da primeira expatriação, o empregado disse que pensava "todos os dias [em sair da empresa] (...) nunca foi o meu objetivo sair da empresa, mas eu ocasionalmente estava numa situação desconfortável". Isso mostra que, por não existir a prática de acompanhamento dos repatriados, se desconhece seu posicionamento, sendo, muitas vezes, a visão da empresa diferente da visão do expatriado.

O Grupo 4 (repatriados que saíram da empresa) revela que a repatriação teve um significado a mais na valorização do crescimento profissional. Estes entrevistados também falaram sobre a mudança de valores pessoais e afirmaram ser possível visualizar um maior desenvolvimento como profissionais. Talvez essa visão esteja vinculada ao fato de eles já não estarem mais na empresa, o que reflete uma postura de quem busca o crescimento profissional individual.

Evidencia-se, portanto, que há uma falha no planejamento do retorno das pessoas, percebida pela maioria dos entrevistados, independente do momento em que estejam vivenciando o processo de expatriação na empresa estudada. Mesmo os expatriados que ainda não passaram por uma repatriação não têm muitas expectativas quanto à volta, por já saberem, pela experiência de outros colegas, os problemas enfrentados na repatriação na empresa em questão. Além disso, eles sabem que o índice de desligamento da empresa está aumentando após a repatriação. Ouve-se com frequência a expressão "quando tu vais, quando é expatriado, tu és a solução de um problema. Quando tu voltas, tu és o problema" (Entrevistado Q - Grupo 4), refletindo que a empresa não está preparada para receber o empregado de volta e, assim, acaba gerando a visão de que o repatriado está se tornando um problema.

A repatriação é marcada pela carência tanto de práticas e políticas na empresa como de uma área que possa implementar isso. Os entrevistados mostram que a falta de clareza, por parte da empresa ou, até mesmo, a inexistência dessas práticas (como a avaliação de desempenho dos expatriados durante o processo, planejamento conjunto de carreira etc.), causa-lhes preocupação, pois eles não sabem o caminho que sua vida profissional vai tomar. Sobre as expectativas criadas, os entrevistados observam que isso é algo que faz parte do ser humano, e que, por terem visto e testado sua capacidade de gerenciar, esperam este reconhecimento na sua volta. 


\section{A Carreira dos expatriados}

Apesar de os empregados planejarem a expatriação como parte do desenvolvimento da carreira (17, dos 19 empregados entrevistados, planejaram ou pensaram a experiência internacional como importante possibilidade de desenvolver sua vida profissional), eles observam que a empresa não tem essa mesma preocupação, inclusive pelo fato de a empresa não contemplar a expatriação/repatriação como uma etapa do plano de carreira profissional. Os repatriados são informados de que irão retornar para a mesma posição que ocupam, conforme estabelecido no contrato, o que faz com que não criem muitas expectativas. Entretanto, isso faz com que o processo de expatriação como um todo represente um impacto negativo na carreira das pessoas (LAZAROVA e CALIGIURI, 2001) devido ao tempo em que ficam afastados de seus cargos. Como refere Tung (1988), "o que os olhos não veem o coração não sente". Logo, o empregado que não está ali, não está sendo lembrado nem pelo seu trabalho nem está sendo reconhecido por seus superiores. Assim, pode-se tornar desestimulante viajar pela empresa, como observa Tung (1998).

Apenas dois Entrevistados (L e O) não tinham a intenção de ser expatriados, entretanto hoje veem a importância que esse processo teve em seu desenvolvimento, tanto profissional como individual. Cabe, pois, questionar se, informalmente, o processo de expatriação não está sendo mais valorizado do que as políticas de carreira da empresa sinalizam. Pode-se relacionar essa questão ao fato de que nos dias de hoje a adaptação e a mobilidade têm sido valorizadas enquanto competências desejadas aos profissionais atuais (FREITAS, 2009) de modo que a expatriação vem tomando um status maior para os seus empregados, do que a empresa lhe atribui.

Percebe-se que, aqui, fruto de uma lógica de trabalho que implica maior complexidade, desempenho constante, desenvolvimento de competências, há um estímulo a esses profissionais se responsabilizarem e investirem mais diretamente no desenvolvimento contínuo de suas carreiras, dentro da propagada necessidade de o indivíduo continuamente investir em si próprio.

Entretanto, na medida em que muitas empresas de vanguarda têm estabelecido processos de gestão compartilhada de carreira, em que as pessoas são responsáveis por seu planejamento de carreira, e as organizações pelo gerenciamento de oportunidades, tal qual apontado por Veloso e Dutra (2010), pode-se entender que essa seja uma expectativa dos entrevistados, profissionais de formação superior, com significativo tempo de casa e idade média em torno de 41 anos. Como já mencionado, a empresa em estudo é importante no cenário corporativo, tanto nacional, quanto mundial em seu setor, é uma empresa de grande porte, líder no mercado brasileiro, preocupando-se com a busca de práticas inovadoras. O processo de expatriação, embora não seja recente na Alpha, é considerado pela área de RH ainda um tema que necessita ser aperfeiçoado, sendo inclusive um dos motivos da abertura da empresa a esse estudo. Na expectativa de uma gestão mais compartilhada de carreira, o fato de não ser discutido o futuro do repatriado na volta para o Brasil faz com que ele muitas vezes se sinta desmotivado no retorno. Foi relatado, nas entrevistas, que o trabalho na expatriação não é valorizado posteriormente, e que isso pode levar à saída do empregado da empresa, pois, a partir do momento em que ela não valoriza o conhecimento adquirido em uma experiência internacional, o empregado irá buscar alternativas fora da empresa, característica presente nas carreiras proteanas (HALL, 1996) e de autogestão (FONTENELLE, 2005).

Em relação ao planejamento da carreira na repatriação, alguns entrevistados observam a responsabilidade que o próprio indivíduo precisa ter para buscar seu espaço e novas oportunidades dentro da empresa. Além de a empresa proporcionar oportunidades para o empregado, este também deve se preparar para assumir novos desafios. Ressalta-se que o fato de o empregado ter passado por um processo de expatriação não representa, necessariamente, ascensão na hierarquia da empresa, mas ganhos de experiência profissional. Apesar da missão, o empregado não recebe promoção automática nem aumento de salário. Dessa maneira, os participantes referem que seria importante que a empresa ofertasse um feedback para eles saberem se estão seguindo o caminho certo para alcançar seus objetivos de carreira. 
Apesar de a maioria dos expatriados/ repatriados ter planejado ou pensado na expatriação como uma forma de incrementar seu desenvolvimento de carreira, poucos são aqueles com quem a empresa discute um plano de carreira claro, com objetivos traçados, o que inclui melhor aproveitamento de competências. Percebe-se que a estrutura da empresa e a atuação do RH não têm conseguido englobar as práticas e políticas necessárias para um adequado planejamento de carreira, o que acarreta desmotivação dos empregados e problemas de retenção.

As oportunidades de crescimento, especialmente as que envolvem cargos estratégicos, são percebidas como consequência de vários investimentos na carreira, o que inclui os anos de experiência. Assim, como bem observam os entrevistados $\mathrm{G}$ e H, para assumir um cargo de tal importância, o empregado deve possuir alguns anos de empresa e, além disso, conhecer toda a sua estrutura, passando por mais de um processo de expatriação.

O sentimento de comprometimento que os empregados têm com a organização e o comprometimento da organização com eles é outro fator ressaltado. Quando a empresa apresenta uma cultura acolhedora, faz com que os empregados se sintam comprometidos com ela e, assim, ao assumirem uma missão, como a expatriação, eles queiram cumpri-la até o fim, independente das dificuldades enfrentadas.

Às vezes bate aquela coisa assim de voltar antes. Acho que não porque assumi um compromisso de ter que ficar os dois anos. Acho que compromisso aceito, seja fácil ou seja difícil, é um compromisso (ENTREVISTADO C - GRUPO 1).

Na medida em que é comum o ser humano criar expectativas e, apesar de terem consciência de que não vão ter crescimento vertical na hierarquia da empresa por terem sido expatriados, alguns entrevistados reconhecem que a expatriação agregou muito a seu desenvolvimento profissional, e isso fará diferença ao longo da carreira. Eles esperam que essa valorização possa trazer alguma vantagem no futuro, criando, pois, expectativa de crescimento, a qual poderá ser ou não correspondida pela empresa em questão. Outros entrevistados são mais cautelosos e observam que ainda há muito para contribuir com a empresa para crescer dentro da organização, e que é necessário tempo para que os objetivos comecem a se consolidar.

Três dos entrevistados tiveram oportunidade de conquistar seu espaço na organização com a repatriação. Um deles observa que o crescimento hierárquico trouxe mais responsabilidades, mas, mesmo assim, não há como comparar com o trabalho realizado quando estava na condição de expatriado, pois "lá fora as coisas fluem mais" (Entrevistado I - Grupo 3).

Em relação à relevância da repatriação para a carreira do indivíduo, a maior parte dos entrevistados apercebe como positiva. É referido que a expatriação, como um todo, agrega um diferencial em seus currículos, e que, quando eles voltam para o Brasil, ficam mais visados na empresa, o que permite que sejam lembrados quando surgem outras oportunidades. Se eles saírem da empresa, o fato de terem tido uma experiência internacional lhes dá vantagem sobre outras pessoas, pois possivelmente permite que a pessoa aprenda, além de uma segunda língua, a lidar com diferentes culturas.

Outro fator relevante relatado é a comparação com as pessoas que ficam no Brasil, as quais continuam com as mesmas atividades. As pessoas que vão viajar têm a oportunidade de se desenvolverem por meio do conhecimento de outros processos. Esses novos processos lhes permitem ter noção mais ampla de toda a cadeia produtiva ou do gerenciamento de uma empresa, o que é considerado muito importante.

Apesar de terem oportunidade de aprendizagem e desenvolvimento profissional, alguns entrevistados expressaram que a repatriação não impactou nas suas carreiras dentro da empresa Alpha, por não haver a valorização desejada, na volta para o Brasil. Outros afirmam que um dos impactos que a repatriação provoca é promover maior confiança para a realização de um bom trabalho, no sentido de tomar decisões mais rápidas e melhores, devido ao maior conhecimento de todo o processo. O Entrevistado $\mathrm{T}$ relata que agora deixa de ter medo e se arrisca mais em suas decisões, sem ter receio de errar, pois ele sente que sua carreira 
interna está sendo desenvolvida e, caso vier a ser demitido, percebe que poderá encontrar outro emprego mais facilmente.

Há um grupo que acredita que a empresa não deve oferecer oportunidades na repatriação, pois consideram que o empregado já teve uma oportunidade importante dentro da empresa, que deve ser valorizada. Para uma minoria, a expatriação já é uma forma de a empresa mostrar que está valorizando seus empregados. As expectativas geradas recaem sobre alguns fatores, como o contrato psicológico da expatriação, abordado por Inkson (2007); o status que a expatriação tem dentro de uma empresa, pois os programas de expatriação são os mais cobiçados dentro de uma organização; a visão do expatriado, que é ampliada na missão, como ressaltam Tanure, Evans e Pucik (2007), Black e Gregersen (1999), Stroh (1995), Lazarova e Caligiuri (2001) e Suutuari e Brewster (2003).

Para o grupo que saiu da empresa, o processo de expatriação como um todo (que inclui a repatriação) teve impacto significativo na busca por outro emprego. Primeiro, em função da experiência internacional, que desperta o interesse de outras empresas; e também pela experiência de vida e pelas situações vividas, as quais fortalecem o desempenho no atual trabalho. Retoma-se a noção de que a expatriação leva à valorização maior da carreira interna, aquela que o indivíduo se dedica ao desenvolvimento de suas habilidades e competências, do que a carreira externa, aquela que se desenvolve dentro da organização em que trabalha (STAHL, MILLER e TUNG, 2002; TUNG, 1998).

Outro fator ressaltado por impactar na carreira é a ampliação do network interno. Quando está no Brasil, em uma empresa grande como a Alpha, dificilmente o empregado conhece os gestores de outras áreas, pois ele se limita a fazer seu trabalho, em sua área. Quando ele está em expatriação, como a estrutura da empresa é menor e a dinâmica de uma expatriação é maior, o empregado passa a conhecer mais pessoas de outros níveis hierárquicos e de outras áreas.

Por exemplo, na empresa no Brasil, um analista de qualidade trabalha sempre no laboratório de qualidade, medindo a qualidade do produto. No processo de expatriação, para medir a qualidade desse mesmo produto, ele tem que ir ao estoque, pegar o produto, levar para o laboratório, medir a qualidade; se estiverem faltando equipamentos, ele tem que buscá-lo, emitir o laudo e, se o produto não estiver conforme o padrão estipulado, ele tem que tomar as providências. Nessa dinâmica, o empregado passa por todos os processos da empresa, e isso faz com ele fique mais "visado" dentro da organização. Por esse conhecimento de pessoas e processos, quando ele volta para o Brasil, pode ter oportunidades de ser lembrado em diversas áreas da empresa, diferentemente dos demais colegas não expatriados.

Eu acho que o que mudou foi a visualização da minha pessoa. Quando tu vai para fora, faz um trabalho que seja a contento da empresa, tu passa a ser conhecido por outras pessoas, tu sai daquele teu mundo e tu passa a conversar com gerente, diretor, com outras pessoas e aí te dá, digamos assim, te torna um pouco mais público para o resto da companhia. Tu te tornas um pouco mais conhecido: "ah, fulano de tal fez tal serviço; ah, o cara fez isso, fez aquele outro". Quando tu vai trabalhar fora e tu tens que ter vontade, tu tens interface com todo mundo: "ah, fala com pessoal da qualidade, gerente, diretor, com todo mundo". Isso é importante (ENTREVISTADO R - GRUPO 4).

Pelos relatos dos entrevistados, percebe-se que ter tido uma experiência internacional não é percebido como fator decisivo para seu crescimento dentro da organização Alpha, mas sim como investimento próprio na carreira. Entretanto, alguns dos repatriados sentem-se desmotivados com o retorno ao Brasil muito mais pela perda da autonomia e pela falta de desafios. Nesse sentido, seria importante que a empresa passasse a valorizar o crescimento desses profissionais não a partir necessariamente de um crescimento hierárquico, mas poder agregar aos cargos outras responsabilidades e desafios para que a pessoa não perdesse sua autonomia (que tinha durante a expatriação) e trabalhasse com eles as novas possibilidades. 
Cabe ressaltar que esse estudo entende a expatriação como um processo amplo dividido em três momentos: a ida, a missão e a volta. Além disso, embora o foco do trabalho esteja no retorno, muitas vezes torna-se importante discutir todo o processo, visto que a experiência é vivenciada pelo repatriado como um todo.

Foi observado que o que mais impacta na relação carreira/ repatriação é a aprendizagem obtida, tanto em termos pessoais, de conhecimento de outras culturas, como profissionais, abrangendo um maior conhecimento da organização e a possibilidade de tomar decisões. É valorizado também o fato de que conhecer outras pessoas pode vir a ajudar em seu crescimento e desenvolvimento dentro ou fora da empresa. Assim, a expatriação/ repatriação tem um impacto positivo na carreira do indivíduo, especialmente por aquilo que lhe agrega enquanto profissional e pessoa. Todos os participantes apresentam percepção positiva da experiência quanto ao que ela agrega, embora reajam a ela de forma diferente. Dos onze entrevistados desse grupo (Grupo 3 - repatriados), dois ressaltam que sua volta ocorreu de maneira positiva; três dizem que tiveram oportunidades que foram surgindo ao longo do tempo; três acreditam que as oportunidades vão surgir e "que tudo vai acabar se acomodando", embora não descartem também outras oportunidades de trabalho. Porém, três repatriados (embora tenham valorizado a experiência da expatriação como um todo) não esperaram por esse momento de acomodação e pensam em se desligar da empresa, porque eles acreditam que foram enviados para solucionar um problema no exterior. No entanto, na volta, acabaram retornando como um problema para a empresa matriz.

Na relação entre repatriação e carreira, observa-se que aos poucos, no caso estudado, os empregados vêm estabelecendo um maior vínculo consigo mesmos, com seu desenvolvimento pessoal e profissional, do que necessariamente para com a organização em que trabalham. Nesse sentido, pode-se novamente relacionar a noção de carreira proteana (HALL, 1996), aquela dirigida pelo indivíduo, que pode ser redirecionada ao longo do tempo, conforme as mudanças pessoais e do meio. Entretanto, destaca-se que ainda almejam um compartilhamento conjunto de expectativas, que traria benefícios à empresa e aos empregados.

Um fator interessante é analisar o tipo de percepção de carreira de cada entrevistado e a relação com a idade e o tempo de casa. Os expatriados mais jovens se concentram no Grupo 4 (repatriados que deixaram a organização) e que a noção de carreira deles está ligada a algo realizado independentemente da empresa. Essa percepção pode estar relacionada ao fato de serem pessoas mais jovens e que têm a ansiedade de buscar melhores empregos, não tendo como foco uma única organização. Essa percepção também pode ter sido alterada após a saída da empresa Alpha, pois, como eles perceberam que há a possibilidade de conquistar novos espaços e investir na sua própria carreira, essa visão pode ter adquirido uma nova perspectiva. Já o Grupo 1 (expatriados recém-enviados) possui, com exceção do Entrevistado A, que foi contratado exclusivamente para a missão, mais tempo de casa (em média, 16 anos), e isso pode estar relacionado com o tipo de percepção de carreira, que é a Carreira Organizacional (DUTRA, 2007; BENDASSOLLI, 2009), que o funcionário tende a desenvolver dentro de uma mesma organização por mais tempo.

No Grupo 2 (expatriados que estão há mais tempo na missão) e Grupo 3 (repatriados que estão na organização), ressalta-se que os Entrevistados E e L, veem as possibilidades de carreira como a Proteana (HALL, 1996). Essa percepção pode estar relacionada com o fato de que o Entrevistado E, nas entrevistas, não acredita que exista espaço para ele dentro da organização, e o Entrevistado L está insatisfeito com as atribuições atuais. Logo, a percepção sobre suas carreiras deixa de ser somente para dentro da organização e amplia-se para o de carreira que pode ser construída independentemente do lugar em que a pessoa está. Dessa maneira, no geral, percebe-se que as pessoas mais experientes, com mais tempo de casa e que não saíram da empresa estão mais centradas no desenvolvimento de sua carreira na empresa Alpha. Além disso, a cultura familiar da empresa e a cultura da região contribuem para que os empregados mais velhos tenham um sentimento de pertencimento àquela organização e busquem se acomodar àquela situação.

Finalizando, o caso estudado aponta para a importância do processo de expatriação para o desenvolvimento da carreira dos profissionais, carreira entendida como uma construção contínua de experiências e de desenvolvimento de competências. Destaca ainda que o modo de condução da repatriação é fundamental para a retenção dos profissionais, pelo investimento financeiro que representa para a empresa e pelo que os 
repatriados trazem consigo (toda uma bagagem de conhecimentos que deveria ser valorizada pela organização).

\section{Considerações Finais}

O conceito de carreira é amplo e tem sofrido alterações ao longo dos anos, estimulado pelas mudanças sociais, econômicas, políticas e culturais. Rompe-se a noção de equiparação entre trabalho e emprego, de trabalho permanente, de contratos a tempo completo e de longa duração, nos quais o vínculo empregatício praticamente era estendido a toda vida produtiva do trabalhador, tornando, assim, o trabalho objetivamente disforme. Assim, mudam-se as relações de trabalho e, consequentemente, o sentido que as pessoas atribuem a ele devido às incertezas que os cercam e à individualização do trabalhador, que se torna o único responsável pelo seu caminho profissional (OFFE, 1989; GUIMARÃES, 2005). Bendassoli (2009) observa que a carreira pode ser compreendida como um processo de individualização, indo além do simples fato de ocupar um cargo para englobar um projeto de vida associado a uma organização ou a uma categoria profissional.

A carreira pode ser analisada dentro de uma perspectiva organizacional, como Dutra (2007) e Blau (2001) ressaltam, mas pode ser vista também em uma perspectiva individual, como sugere Bendassoli (2009), ou até mesmo como uma atividade fora do emprego, conforme a abordagem de Ivancevich (2008) e Inkson (2007). A percepção sobre a carreira tem evoluído, e novas concepções surgem. Entretanto a nova configuração da carreira, impulsionada pela globalização, pelo sistema capitalista e pela competitividade acirrada, direciona para uma perspectiva individual, a qual é planejada apenas pela própria pessoa e não mais com a empresa. $\mathrm{O}$ planejamento e o desenvolvimento da carreira dentro de uma organização não ocorrem isolados dos fatores ambientais e pessoais, envolvendo tanto as ambições profissionais do indivíduo, como as propostas da empresa.

Entende-se que o desenvolvimento profissional passa por várias etapas. Cabe a cada indivíduo buscar inovar sua carreira, a qual vai tomando, cada vez mais, novas configurações. O planejamento e o desenvolvimento profissional do empregado ocorrem por intermédio das necessidades organizacionais e individuais. Uma das possibilidades que o profissional encontra para se destacar no meio empresarial é através de experiências internacionais que podem representar oportunidades de crescimento na carreira e de desenvolvimento profissional, assim como da sua empregabilidade.

A pesquisa buscou analisar as expectativas geradas pela repatriação e as mudanças em termos de carreira, a partir de uma experiência profissional internacional. A experiência internacional configura-se como uma das maneiras de inovar sua carreira organizacional. Muitos profissionais acreditam que por meio dessa experiência terão crescimento vertical na hierarquia da empresa ou enriquecimento nas atividades realizadas, quando retornarem ao país de origem. Essa tem sido, entretanto, predominantemente uma expectativa não correspondida, como refere a literatura e indica o caso estudado.

Na expatriação da empresa Alpha, os empregados exercem atividades mais amplas e têm maior autonomia, o que eles valorizam muito. Ao retornarem, os agora repatriados percebem que tiveram uma oportunidade importante de aprendizado e desenvolvimento profissional e, por isso, esperam a valorização por parte da organização destes aspectos, o que nem sempre ocorre da maneira esperada.

Os repatriados percebem-se retornando para o mesmo lugar, como se nada, para a organização, tivesse acontecido. Assim, essa ampliação de seus conhecimentos atrelada à desvalorização percebida - devido à redução de responsabilidades e desafios - causa grande frustração. Outro fator que contribui para essa nova percepção é o sentimento de que o empregado, durante a experiência internacional, abdica de seu cotidiano e compromete-se com a organização ao assumir importantes projetos, diferentemente de uma viagem de negócios usual. 
Em termos de carreira dentro da organização, percebem que a experiência internacional vivida não causou o esperado impacto. O repatriado, então, passa a valorizar a sua carreira interna, aquela que se agrega ao indivíduo, e não mais somente a carreira desenvolvida dentro da organização.

Nesse sentido, destaca-se no estudo conduzido que a experiência internacional foi valorizada por possibilitar a aprendizagem, o crescimento profissional e individual, a ampliação da visão estratégica, como forma de auxiliar no desenvolvimento da carreira, na maior competência para a tomada de decisão e na ampliação do network interno.

Um levantamento de como ele pode contribuir com a organização e de que forma a empresa pode melhor reconhecer este processo precisaria ser feito. Como outros desafios, destacam-se a necessidade de maior conciliação das expectativas da empresa com as do empregado, ampliação das possibilidades de atuação do $\mathrm{RH}$, retenção do conhecimento do repatriado e planejamento compartilhado de carreira.

Como ressaltado por Dutra (2007), é importante conciliar os objetivos da empresa com as expectativas dos empregados. Apesar de a empresa ter 21 anos de internacionalização e 12 anos de processo de expatriação, o seu principal objetivo é levar conhecimento para as empresas subsidiárias e ter pessoas de confiança para gerenciar as empresas. No entanto, como apontado, os repatriados nutrem uma expectativa de desenvolvimento de carreira, tanto individual como organizacional, atrelada à experiência vivida.

Além disso, a média de idade dos entrevistados é de 41 anos e o tempo médio de empresa é de 13 anos. Assim, muitos entrevistados têm expectativas de assumir uma função gerencial, em função do tempo de dedicação à empresa e a sua maturidade profissional, especialmente depois de terem desenvolvido uma experiência internacional. Vão, a organização coloca outro em seu lugar, voltam, sentem que passam por despercebidos pela organização que pouco valoriza a experiência de desenvolvimento profissional; vão como a solução e sentem-se, muitas vezes, retornando como problemas (se percebem, enquanto problema: e agora, nada muda? Será que não considerarão tudo que vivenciei?), sentimento que acaba sendo passado para os empregados em geral.

Conclui-se que a relação entre expatriação e carreira, no caso da empresa Alpha, é percebida de forma marcante para o repatriado, bem mais do que para a própria organização. Tal fato traz consequências para os que vivenciam essa experiência, bem como para a empresa, que muitas vezes perde conhecimento em não reter os repatriados.

Uma das maneiras percebidas que a empresa tem de valorizá-los é oportunizando a eles maiores desafios ou cargos com responsabilidades mais amplas, de modo que eles possam continuar a exercer atividades desafiadoras e exigentes. Vários entrevistados ressaltam que o que importa para eles é ter autonomia, responsabilidades e desafios, o que não necessariamente precisa vir conjugado à ascensão de cargo.

Esta pesquisa centrou-se em um estudo de caso, portanto, não sendo possível generalizar os resultados para todas as empresas que possuem programa de expatriação. Entre os fatores limitadores do estudo encontra-se o país para o qual o expatriado é enviado, pois, dependendo dos aspectos culturais do país e da estrutura da empresa, o processo pode transformar-se em experiência positiva ou negativa, e isto a empresa não tem como controlar. As sugestões de práticas propostas no presente trabalho podem, entretanto, ser adotadas por outras organizações, desde que seja avaliada a forma de aplicação.

Este estudo procurou discutir o processo de expatriação, caracterizado como um componente estratégico dentro das organizações, considerando que nem sempre há espaço para investigar como realmente acontece. Demonstrou a lacuna que existe entre expatriação, considerando sua importância para a organização, e a repatriação, momento igualmente relevante, que, entretanto, acaba, muitas vezes, sendo menos valorizado, "esquecido" pela empresa, ou sendo "naturalmente ajeitado". 


\section{Referências}

BARDIN, L. Análise de conteúdo. 3. ed. Lisboa, Portugal: Edições 70, 2004.

BENDASSOLI, P. F. Psicologia e trabalho. Apropriações e Significados. São Paulo: Cengage Learning, 2009.

BLACK, J. S.; GREGERSEN, H. B. The Right Way to Manage Expats. Harvard Business Review, mar./ abr., p. 52 62, 1999.

BLAU, G. On assessing the construct validity of two multidimensional constructs Occupational committed and occupational entrenchment. Human Resource Management Review, v. 11, p. 278 - 298, 2001.

BOHLANDER, G.; SNELl, S.; SHERMAN, A. Administração de Recursos Humanos. São Paulo: Pioneira Thomson Learning, 2003.

BROOKFIELD GLOBAL RELOCATION SERVICES. Global Relocation Trens. 2010 Survey Report. Estados Unidos, 2010. Disponível em: <http://www.brookfieldgrs.com/insights_ideas/grts/grts_thanks.asp> Acesso em: 30 nov. 2010.

CALIGIURI, P. M. Selecting expatriates for personality characteristics: a moderating effect of personality on the relationship between host national contact and cross-cultural adjustment. Management International Review, v. 40, n. 1, p. 61-80, 2000.

CHANLAT, J. F. Quais Carreiras e para Qual Sociedade (I)? Revista de Administração de Empresas, v. 35, n. 6, p. 67-75, nov.-dez., 1995.

DEMO, P. Metodologia do conhecimento científico. São Paulo: ATLAS, 2000.

DERESKY, H. Administração global: estratégica e interpessoal. Porto Alegre: Ed. BOOKMAN, 2004.

DUTRA, J. S. Gestão de pessoas. Modelo, Processos, Tendências e Perspectivas. São Paulo: ATLAS, 2002.

Administração de carreira. Uma Proposta para Repensar Gestão de Pessoas. São Paulo: Atlas, 2007.

FONTENELLE, I. A. "Eu Proteu": A auto-gestão de carreira entre fatos e mitos. In: Encontro nacional dos programas de pós-graduação em administração, 29, 2005. Brasília, Anais... [S.I.]: 2005. CD-ROM.

FREITAS, M. E. A mobilidade como novo capital simbólico nas organizações ou sejamos nômades? O\&S, Salvador, v. 16, n. 49, p. 247-264, Abr./ Jun., 2009.

GODOI, C. K.; MATTOS, P. L. C. L. Entrevista qualitativa: instrumento de pesquisa e evento dialógico. In: GODOI, C. K.; BANDEIRA-DE-MELO, R.; SILVA, A. B. (Orgs.). Pesquisa qualitativa em estudos organizacionais. Paradigmas, Estratégias e Métodos. São Paulo: Saraiva, 2006.

GONZÁleZ, J. M. R.; OLIVEIRA, J. A. O. Os efeitos da expatriação sobre a identidade: estudo de caso. Cad. EBAPE.BR, v. 9, n. 4, p. 1122-1135, 2011.

GUIMARÃES, N. A. Trabalho: uma categoria-chave no imaginário juvenil? In: ABRAMO, H. W.; BRANCO, P. P. M. (Orgs.) Retratos da Juventude Brasileira: análises de uma pesquisa nacional. 1 ed. São Paulo: Fundação Perseu Abramo, 2005.

HALL, D. Protean careers of the 21st century. Academy of Management Executive, v. 10, n. 4, p. 8-16, 1996.

HERMAN, J. L.; TETRICK, L. Problem-focused Versus Emotion-focused Coping Strategies and Repatriation Adjustment. Human Resource Management, v. 48, n. 1, p. 69-88, 2009.

INKSON, K. Understanding Careers. The metaphors of Working Lives. London: Sage publications, 2007. 
IVANCEVICH, J. M. Gestão de recursos humanos. 10. ed. São Paulo: Mcgraw-Hill, 2008.

KOHONEN, E. The impact of international assignments on expatriates' identity and career aspirations: Reflections upon re-entry. Scandinavian Journal of Management, v. 24, p. 320 - 329, 2008.

LAZAROVA, M.; CALIGIURI, P. Retaining repatriates: The role of organizational support practices. Journal of World Business, v. 36, n. 4, p. 389-401, 2001.

; CERDIN, J. L. Revisiting repatriation concerns: Organizational support versus career and contextual influences. Journal of International Business, v. 38, p. 404-429, 2007.

MENDENHALL, M. E.; ODDOU, G. The Dimensions of Expatriate Acculturation: A Review. Academy of Management Review, v. 10, n. 1, p. 39-47, 1985.

OFFE, C. Trabalho: a categoria sociológica chave? In: OFFE, C. Capitalismo desorganizado: transformações contemporâneas do trabalho e da política. São Paulo: Brasiliense, 1989.

SCHEIN, E. H. Career Anchors Revisited: Implications for Career Development in the 21st Century. Academy of Management Executive, v. 10, p. 80-88, 1996.

STAHL, G. K.; MILLER, E. L.; TUNG, R. L. Toward a boundary less career: A closer look at the expatriate career concept and the perceived implications of an international assignment. Journal of World Business, v. 37 , p. 216 - 227 , 2002.

STROH, L. K. Predicting Turnover Among Repatriates: can organizations affect retention rates? The International Journal of Human Resource Management. v. 6, n. 2, p. 443-456, 1995.

; GREGERSEN, H. B; BLACK, J. S. Closing the Gap: Expectations versus Reality Among Repatriates. Journal of Business, v. 33, n. 2, p. 111-124, 1998.

SUUTARI, V. Global managers: Career orientation, career tracks, life style implication sand career commitment. Journal of Managerial Psychology, v. 18, n. 3, p. 185-207, 2003.

; BREWSTER, C. Repatriation: Empirical evidence from a longitudinal study of career sand expectations among Finnish expatriates. International Journal of Human Resource Management, v. 14, n. 7, p. 1132-1151, 2003.

TANURE, B.; EVAnS, P.; PUCIK, V. A Gestão de Pessoas no Brasil. Virtudes e Pecados Capitais. Estudos de Caso. Rio de Janeiro: Elsevier, 2007.

TUNG, R. L. Selecting and Training Procedures of U.S., European, and Japanese Multinational Corporations. California Management Review, v. 25, p. 57-71, 1981.

1988.

Career Issues in International Assignments. The Academy of Management Executive, v. 11, n. 3, p. 241-244,

American expatriates abroad: from neophytes to cosmopolitans. Journal of World Business, v. 33, n. 2, p. 125-144, 1998.

VELOSO, E. F. R.; DUTRA, J. S. Evolução do conceito de carreira e sua aplicação para a organização e para as pessoas. In: DUTRA, J. S. Gestão de carreiras na empresa contemporânea. São Paulo: Atlas, 2010.

WEBB, A.; WRIGHT, P. C. The expatriate experience: implications for career success. Carrer Development International, n. 1, v. 5, p. 38-44, 1996.

YIN, R. Estudo de caso: planejamento e métodos. 3. ed. Porto Alegre: BOOKMAN, 2005. 